\title{
Exploring Research and Contextual Relevance in Engineering Education: The Case of a University in South Africa \\ Kehdinga George Fomunyam
}

\begin{abstract}
The need for improvement in production and processes and to have a better approach to it necessitates the imperative of engineering education. The practice of engineering education takes place in a context and it is also influenced by the context in which it takes place. Context is the cultural framework or environment in which technical knowledge and skills are learned. Globally, there are changes along socio-economic, environmental, and demographic lines and its driving profound changes in engineering education in the society. This study explored research and contextual relevance in engineering education using a South African University as a case study. The choice of University of cape town for this case study was informed by the ranking of the institution as one of the best universities of engineering in South Africa. The university also has a center for research in engineering education from which research focus was picked to establish its relevance. Findings from this study revealed that engineering research takes place Disciplinary, environment, economic, social, cultural, political context. From the study, it was revealed that university of cape town has five major research focus in engineering education which include teaching and learning in science and engineering, students in transition, knowledge and curriculum, higher education policy and institutional dynamics and evaluation and development of methodologies. These thematic areas were explored for contextual relevance. The study recommended that The study recommends that effort be placed more on research on digitization to ensure relevance with the current clime and also, researches in University of Cape Town should be tailored towards the Fourth Industrial revolution for relevance
\end{abstract}

Keywords: Engineering, Research, Engineering Education, South Africa, Context, Contextual Relevance.

\section{INTRODUCTION}

Engineering education serves as an academic ground for industrial and technological burden placed on future engineers which has the capacity to cause a change in technological advancement and improve the welfare of humans (de Graaff \& Ravesteijn, 2001; Berggren et al., production and processes and to have a better approach to it necessitates the imperative of engineering education. The practice of engineering education takes place in a context and it is also influenced by the context in which it takes place. Context is the cultural framework or environment in which technical knowledge and skills are learned.

Revised Manuscript Received on May 30, 2020.

* Correspondence Author

Dr. Kehdinga George Formunyam*, Teaching and Learning Development Center, Mangosuthu University of Technology, South Africa.

(c) The Authors. Published by Blue Eyes Intelligence Engineering and Sciences Publication (BEIESP). This is an open access article under the CC BY-NC-ND license (http://creativecommons.org/licenses/by-nc-nd/4.0/) 2003; Grimson, 2002). The need for improvement in

Understanding the context in which engineering education research take place is vital for decision making. People are often of the opinion that if a research works in a country, it might be applicable elsewhere. There are differences in countries of the world and what obtains in a place might not be possible in another hence the need to have understand research and contextual relevance in engineering education. Globally, there are changes along socio-economic, environmental, and demographic lines and its driving profound changes in engineering education in the society. It is important to note that as the society changes, areas that necessitates requests for new skills emerge and this must be faced with new approaches to learning. The requirements for $21^{\text {st }}$ century engineers include technical competence, global sophistication, cultural awareness, innovation and entrepreneurial abilities, flexibility and mobility (Continental, 2006) which necessitates the need for contextual relevance. With new areas that require new skillset emerging, there must be relevant ways of approaching such learning (Adams, Kaczmarczyk, Picton, \& Demian, 2010; Graham \& Crawley, 2010). This implies that the new approaches to learning must be contextually relevant. This implies that the situation in which the discipline of engineering education is carried out, the group of conditions that surrounds it must be relevant.

Looking back one can attest to the changes that have taken place in the fabric of civilization. These are times of profound and rapid transformation and there has been a transition from agriculture to one of rapid industrialization brought about by technological development. Context in this research will focus on the environment, globalization, demographics, technological change and technological innovation. This research will focus on Challenges in engineering education research, conceptualization of context, analysis of context in which engineering research takes place (environment, geography, culture, economy) and explore context in research.

\section{LITERATURE REVIEW}

Taking a global perspective at engineering education, investment in research in engineering education has been a major priority in the United States and the reason for this was to maintain global competitiveness in the American knowledge based economy. This was manifested in the decision of President Obama to make STEM education a national priority and to intensify efforts on it (Whitehouse.gov.2009). This depict the importance of engineering education as a vital tool for ensuring relevance and dominance among countries in the international sphere. With different changes taking place recently, 
there is a need to brace up to adapt to these changes in order to ensure relevance. The engineering problems of the 20th century can no longer be solved with the curriculum developed then as it is obsolete and not in touch with current realities. The whole engineering dynamic has changed and there are various emerging areas which combines physical, biological and digital technology to cause massive changes in production processes. To brace up to this challenge, there is a need to develop competencies and new skills so as to remain relevant. Some of the skills that are important in this current clime include problem solving, design and analytical thinking (Whitehouse.gov.2009), leadership, emotional intelligence etc.

Engineering education has assumed a face lift and its conduct has changed over time. The traditional conception that emphasizes work roles only within engineering lines has been influenced. Engineering graduates are now involved in other disciplines such as business, finance, management, policy, social and developmental studies etc. as argued by (Borrego, M.; Bernhard, J, 2011), it was noted that the definition of engineering education in the future should be broadened so as to facto in trends, roles and functions of modern and future engineering.

To advance innovation in technical engineering, there is a need to develop a broader approach to research in engineering education (Melsa J, 2007: -Borego M et al , 2009). This typifies the need for huge investments in engineering education research which many countries in the developing world might not be able to cope with. With mass poverty characterizing many developing countries, there has been poor focus on education which is vital in creating a knowledge based economy that can contribute to innovation and hence economic development in the region. Poor investment in research and education has been a major bane for development in countries in the global south which South Africa is a part.

A report from Research and Markets featured on GlobeNewswire (2019) revealed that education and culture received the largest share of the budget totaling around national budget and 6\% of the Gross Domestic Product which is one of the highest among countries in Sub-Saharan Africa. With this investment in education, the educational sector is still in crisis as a result of dysfunctional public school system, low completion rates etc. the South African educational sector according to the research conducted is failing the economy. This figures are low compare to those from developed countries like the United States. According to (White. R.M et al, 2010) it has been estimated that several billions of dollars have been directed towards STEM education, research and development which engineering education is a major part of. This shows a divide between developed and developing countries on the imperative of investment in research and development in order to ensure economic growth. Research in engineering education is important in having a relevant curriculum that will ensure appropriate teaching and learning experience for both teachers and students and to overcome challenges faced in the workplace (NRC, 2007, White R.M et al, 2010).

There are growing concerns that the teaching and learning methods in engineering education are becoming obsolete and cannot meet up with the current realities and future requirements of engineering graduates. This has resulted to various calls, protests and actions on decolonization of R262.4bn. education in South Africa takes about 20\% of the

engineering curriculum in South Africa. As a result of British colonization, there has been a perpetuation of western ideologies in the university education in South Africa. Upholding western views about the local culturally relevant content and context creates a divide between the curriculum and the general output of the teaching learning experience. This typifies the need for contextual relevance in research which can only be made possible by considering the environment, political, social and cultural factors which influences the practice of engineering education in South Africa. Mgqwashu (2016) argues that academics in South African higher education institutions are trying to purge their educational institutions of the procedures, processes, practices and beliefs which sees or describes concepts, practice not white or European as inferior and decolonizing the curriculum is key in the process.

\section{Conceptualization of Context}

The study of context spans a lot of discipline and context from the Latin word contextus which means to weave. Context also means the circumstances in which a situation or an event arises. This implies that in order to understand certain information, context is key and we must explicitly assess the context that surrounds that event. This definition is widely used and people are quite familiar with social context, economical context. Environmental context etc. Context is vital in all disciplines and in engineering design, context has been argued by (The MOKA Consortium, 2001) as that which surrounds it and makes it more valid. Hence, this implies the whole mix of activities surrounding the discipline which gives meaning to it. With stability in every day parlance an illusion, changes are bound to happen. With things evolving in a rapid manner and changing constantly, there is a need to adapt to ensure success. Hence, the imperative of context in each discipline.

\section{Analysis of Context in Which Engineering Research Takes Place (Disciplinary, Environment, Economic, Social, Cultural, Political)}

\section{Disciplinary context}

Modern engineering started as a scientific revolution in the 1600s and it emerged from scientific discovery and methodological development. In the United Kingdom, engineering started as a form of apprenticeship (Watson, 1982). In the works of Culligan and Pena-Mora (2010), John Smeaton established the practice of engineering as a discipline in England.

\section{Cultural context}

The cultural context of engineering education is characterized by issues relating to values, heritage, origin, racial differentiation, ethnicity. These cultural factors are necessary and relevant in the discipline of engineering education as they have the potential to influence it. An engineering outlook at cultural issues will reduce many controversial problems and isolate the root causes of many issues. Culture is a vague set of basic assumptions and values, orientations to life, beliefs, policies,
Blue Eyes Intelligence Engineering \& Sciences Publication 
procedures and behavioral perspectives maintained by a group of people and that influences them but do not determine individual behavior and interpretation of the reasons for other people's behavior (Spencer-Oatey, 2012).

Hofstede maintained that culture is the collective programming of the mind that separates one member of a group from the other. Cultural context is a factor to consider in engineering education in South Africa and it influences the practice and conduct of the discipline.

It is important to note that engineering education in South Africa has in it various individuals, with different background and cultural heritage. With this differences in culture, there are challenges for teaching and learning processes in engineering education. Culture holistically has a bearing on education and according to Obanya (2005) the two cannot be separated. With the diversity in engineering education which is manifested in various individuals from various backgrounds, each seeks to maintain his cultural identity above others. This can be manifested in

Culture furthermore has an influence on behavior and the ability to adapt to changes (Kagerer \& Gandarilla, 2011). The university is a huge space that affects student's behavior. With different individuals from different cultural backgrounds interacting together, students are exposed to attitudes, views, perspectives etc that influences them.

Culture is also important in engineering education as it shapes attitudes, values, knowledge base, skill set and this consequentially influence behavior in the classroom, study habits, writing styles and interaction with others (ECTE, 2005). This implies that culture might have an influence on the overall interaction of the students along engineering education lines.

Culture predominant in specific places also influences the practice of engineering education. In developing countries for instance, patriarchy is still a major feature of most countries there. A socio-cultural tendency to encourage male domination in the society influences the practice and conduct of engineering education there. The popular notion in such countries is that engineering profession is meant for the male gender and it might be difficult for the females to grasp. This view is manifested in enrollment rates into engineering education profession in Nigeria which has in it larger number of males compared to females. Females are often seen as weak and they are culturally sidelined from the discipline. There are changes to this narrative now and there has been clamor for gendered approach to issues in all developmental processes. This has encouraged male domination in the practice of engineering education in Nigeria. This typifies the influence culture has on the practice of engineering education in Nigeria.

The ECTE (2005) revealed that in some cultures, it is mandatory for students to remain silent in class and in some other cultures there are much formality and students maintains respect by standing when a professor enters the classroom. Interaction which is different according to culture can influence the rapport between students and lecturers in engineering education and this influences the discipline. Some cultures encourage collaborative learning and this involves interaction between teachers and students in a community and members interact to acquire and share knowledge and experience (Zhu, 2012). Collaborative learning is a process where students cooperatively work together to complete tasks given by lecturers. In some communication, dressing etc.

cultures, group dynamics as an element of culture is practiced in a formal and sustained manner with much premium placed on interdependence and collaboration than on individual performance (ECTE, 2005). This cultural differences influences the practice of engineering education and from this perspective, success can be measured jointly or individually. Culture influences engineering education and this is manifested in various dimension such as in design. In Nigeria, as a result of socio-economic differences and cultural backgrounds, building designs are different and specific to certain regions. Rikko \& Qwatau (2011) maintained that traditional is a form of cultural heritage maintained from generation to generation, accepted and practiced by the population therein. The cultural differences are manifested in various traditional architecture and it's a pointer to what culture is prevalent in an area. hence, culture influences the material, physical, spiritual and social design of the society (Olotuah, 2001). In engineering education, the type of housing pattern prevalent in an area vary with customs and culture. This is in line with the findings of Rikko \& Qwatau (2011) which maintained that different traditional housing forms at different regions in Nigeria are necessary as an effort to ensure comfort which is influenced by culture, religion, climate, closeness to civilization and expertise. Also, religion as an element of culture, determines the forms, groupings and production of engineering structures in Nigeria. this has evolved recently and the Nigerian engineering scenery is being characterized by postmodern structures and massive sprawl of new designs which has raw materials notably from other countries such as china (Ruquayya Tofa, 2011). As a result of cultural influence, there is adoption of engineering styles from other locations which influences the practice of engineering education in Nigeria.

\section{Political context}

Political forces play a dominant role in influencing and shaping the conduct of engineering education in South Africa. Also, engineering education has impacted on by power, social and economic factors, which include the environment, water availability, education, housing, income distribution, employment, communication and transportation etc. These are dimensions whereby politics influences engineering education and it will be expatiated on in this study.

In South Africa, politics is a significant determinant in engineering education and it influences it. Taking a cue from recent happenings in South Africa, a 2017 report by Mckinsey revealed that by 2030, at least a third of the $60 \%$ activities might become automated. These are huge changes that will come with the fourth industrial revolution which has in it many emerging technologies like artificial intelligence, 3D printing and so many others. With this events, this resulted in political influence on the University in South Africa.

This resulted in the appointment of Professor Tshilidzi Marwala from University of Johannesburg by current president of South Africa Cyril Ramaphosa to appoint members of a presidential commission on the fourth industrial revolution to make policies that will guide South Africa in its quest to become reputable in the digital world 
With the president as the chairman of the committee., he announced the appointment of a deputy chair to the commission who is a professor from University of Johannesburg by the name Tshilidzi Marwala with notable expertise in the theory and application of artificial intelligence to engineering, computer science, finance, social science and medicine.

This clearly typify the political context of engineering which politics influences engineering education as the political trajectory tilted towards the university to create better development plan in the area of engineering and technology for the nation. With the professor's expertise in artificial intelligence, other key areas such as engineering education, computer science, finance, social science and medicine will be influenced.

\section{Environmental context}

The environment is also a key factor that influences the practice of engineering education in South Africa. The environment is a set of materials (biotic and abiotic) that creates a dynamic and interconnected system in certain territory. The environment is also a composite of natural natural and manmade landscape. Environmental context dictates the types of engineering design that will be applicable in a particular area (Fatiregun, 1999). This environmental factors include rainfall and sunlight and all elements related to the climate. There exists a nexus between the environment and engineering education as a discipline. The environment influences engineering education and engineering education influences the environment.

Like it has been reiterated above that environmental conditions dictate the type of engineering designs and structures that are specific to each geographical location. For instance, erosion, desiccation, dissolution, volume change etc. are all affected by environmental conditions such as precipitation and sunlight. With the climate change manifesting with grievous consequences recently, erosion has impacted on the type of construction carried out generally. So also does sunlight has increased tremendously which has the capacity to change the volume of materials. This environmental conditions can affect transport, transformation, dispersion, emission, pollution and damage. As engineering education is developing, there is massive proliferation of mechanical devices to aid the process and in the discharge of duties, these mechanical devices releases dangerous gases which in turn influences the environment which typifies the relationship between the environment and engineering education. A report by Clarice Awa (2019) revealed that in Qatar, some roads are being painted blue for cooler temperature amidst extreme heat caused by climate change.

\section{METHODOLOGY}

This study is conducted as a case study. According to Neuman (2006) a case study is a comprehensive study of a specific case and this case might be an individual, a university, an environment, an organization, a movement, a body, a geographical location etc. as seen from the research topic, this study is a case study of a South African University and University of Cape town South Africa was chosen as a case study to enable the researcher generate education in South Africa and it is a dimension through elements such as land, soil, fossil, water, air, flora, fauna,

robust and in-depth data on the research and contextual relevance in engineering education in the institution. Cohen, Manion, and Morrison (2011) explained that a case study is applicable in qualitative research and the qualitative approach to research aims at exploring every detail about an issue or a case. It reveals the quality the concept being studied (Nieuwenhuis, 2010). The choice of University of Cape Town for this case study was informed by the ranking of the institution as one of the best universities of engineering in South Africa. The university also has a center for research in engineering education from which research focus was picked to establish its relevance.

\section{Evaluating Contextual Relevance of Engineering Education In University Of Cape Town South Africa}

The contextual relevance present in research plays a vital role in assessing and implementation of recommendations made in the paper. From literature, a measure of contextual relevance in research Methodology is content link analysis and from the university, it was revealed that the institution has five key research areas which are teaching and learning in science and engineering, students in transition, knowledge and curriculum, higher education policy and institutional dynamics and evaluation and development of methodologies. This will be evaluated to reveal the contextual relevance of each research focus. Contextual relevance is a construct and it has no universally accepted definition so, for the purpose of this study, I will conceptualize contextual relevance as outcome of research that are directly applicable and suitable to real world issues, socio-economic problems, environment, culture and polity. This will be explained viz-a-viz the research focus.

\section{Teaching and Learning in Science and Engineering}

This focus area centers on research which is concerned with improving classroom practice and student learning. The institution studies innovative pedagogies in science and engineering and also explore the ways in which different pedagogies challenge and/or enable learning. In context, there is a need to have an overhaul in teaching and learning in South Africa so as to ensure that the curriculum in engineering education is contextually relevant. Along this line is the need to incorporate information and communication technologies into the curriculum which has gained wide reception among academic institutions in Africa. Although, in Africa, ICTs have been integrated in instruction design in various teaching courses ( Barakabitze, et al, 2015). As a result of changes in the school curricula in South Africa, it influenced the preparedness of students for tertiary studies especially in courses that has mathematics in its domain such as sciences and engineering as a result of changes in the government, there was a need to change the curriculum which has happened since 1994 (Jansen, 1998). As a result of teaching and learning being racially and provincially segregated in the apartheid era, there was the need to have a unified national curriculum. This can be likened to be an avenue where teaching and learning was overhauled to ensure contextual relevance in science and engineering. This typifies that teaching and learning in science and engineering is contextually relevant in Africa. With recent proliferation of various technologies and the emergence of the fourth industrial revolution, 
researches in South Africa has been on investigating the efficacy of using technologies to aid student engagement and learning. We explore science and engineering students' disciplinary knowledge and skills and the assessment experiences in learning. We are interested in the development of academic, scientific and technological literacy's and students' induction into disciplinary discourses in science and engineering. The fusion of technology and academics is a veritable research area to look into in University of Cape Town and considering the time we are in now; it can be said of such research focus to be contextually relevant. The research focus teaching and learning in engineering education also includes the design of the curriculums; the dominant teaching and assessment approaches and the pattern of implementation; dependence on western knowledge for the curriculum content; the focus on the exportation of research outputs published in foreign countries; the divide between students and lecturers in the classrooms, as well as the university management; and the lack of inclusion of the epistemology of the students into the university.

\section{Students in Transition}

This focus area concerns the way in which students navigate transitions. Navigation in this sense implies the various stages of progression from academic status to another. With the transition from school to university and from university to the outside world, other transitions within higher education are considered such as moving from the supportive environment of a first-year extended degree programme into a mainstream programme, moving from a discipline to another such as from natural to engineering sciences, the transition from the engineering sciences to design, from convergent to divergent problems, as well as the transition into postgraduate studies. With the emergence of the global economy where there is a demand for skills, higher education and training, there is a need for new forms of education management to have the desired outcomes (Deem and Brehony, 2005) which necessitates these transition. With the demand for competent graduates, the educational institution must always seek to produce graduates with defined skill set such as employable skills and general skills that will encourage their transition from the academic institution into the world (Kadhila, 2018). It is therefore imperative as a matter of contextual relevance to consider the difficulties in transition from various levels along the educational line and proffer solution to them as encouraged by university of Cape Town's center for research in engineering education. There have been lots of changes in the higher education programmes in the last few decades (Tomlinson, 2012). Putting this into consideration will ensure that efforts made will result in contextual relevance for engineering education.

\section{Knowledge and Curriculum}

This research area focuses on science and engineering disciplinary knowledge, its place in the workplace, the academy and the undergraduate curriculum, noting that these are different bodies of knowledge. As a result of westernization of the curriculum, there has been various calls for decolonization of the curriculum. So having education will ensure contextual relevance in engineering thereof, as well as their conceptions, identities and researches on knowledge and curriculum in engineering

education. To suit context in higher education in South Africa, Fomunyam et al, (2017) emphasized the need for curriculum responsiveness and he opined that there is a need for employability or economic responsiveness, classroom or cultural responsiveness, disciplinary responsiveness and pedagogical or learning responsiveness. These are strategic research areas the university of cape town research has focused on with particular emphasis on knowledge and its dynamics vis-à-vis the curriculum.

\section{Higher Education Policy and Institutional Dynamics}

This focus area embraces the broader context in which tertiary engineering and science educator's work. Having a broader perspective to engineering education is vital in ensuring contextual relevance. This includes engagement with teachers and lecturers in other disciplines within the space of higher learning, matters pertaining to university administration, organization and management, issues of inter-institutional collaboration or comparison, government policy matters, research into schools, with parents of higher education students or workplace practitioners, as well as the interface with professional bodies. The outward-looking nature of this focus area inherently changes the way in which the research is formulated and disseminated. Since the emphasis is on the societal context in which science and engineering educators work, the research carried out in this area tends to focus on the systemic, organizational and structural dynamics pertaining to higher education hence its relevance.

\section{EVALUATION AND DEVELOPMENT OF METHODOLOGIES}

Methodology concerns the philosophical justification for a research design and the choice of data collection and analysis methods. In university of Cape Town, most researches employs triangulation in their methodology which is the use of a variety of methodologies. This will ensure that multiple referents are drawn to give credence to research conducted and ensure its contextual relevance. For those whose initial education was in science or engineering, there is an intellectual journey to grapple with the various methodologies in social science research. Although it might be seen that the vital issue is the distinction between qualitative and quantitative data, in actual fact this is less significant than being able to vehemently defend a wider methodological position, informed by ontological and epistemological commitments.

\section{FINDINGS/DISCUSSION}

Research and contextual relevance is important to ensure that outcome of various educational pursuits is worthwhile. Findings from the study reveal that there are changes along socio-economic, environmental, and demographic lines and its driving profound changes in engineering education in the society. It was also found out that the requirements for 21st century engineers include technical competence, global sophistication, cultural awareness, innovation and entrepreneurial abilities, flexibility and mobility (Continental, 2006) which necessitates the need for contextual relevance.

Published By: 
Also with the changes taking place, there is a need to brace up to adapt to these changes in order to ensure relevance. The engineering problems of the 20th century can no longer be solved with the curriculum developed then as it is obsolete and not in touch with current realities. The whole engineering dynamic has changed and there are various emerging areas which combines physical, biological and digital technology to cause massive changes in socioeconomic activities. Context was conceptualized as the circumstances in which a situation or an event arises and contextual elements in engineering education were analyzed. Some of them are disciplinary context, environmental context, cultural context, political context, and cultural context.

Findings of the study reveal that University of Cape Town has five key research areas which are teaching and learning in science and engineering, students in transition, knowledge and curriculum, higher education policy and institutional dynamics and evaluation and development of methodologies. These thematic areas were explored for contextual relevance.

\section{CONCLUSION AND RECOMMENDATION}

The major goal of engineering education is to prepare students who are deeply knowledgeable of the technical fundamentals and broadly prepared with the skills of engineering. This study has explored research and contextual relevance in engineering education using the University of Cape Town as a case study. The essence of the case study was to explore details peculiar to the institution along engineering education lines. Engineering education exist within a context that is constantly evolving and this study pointed out the various context in which engineering education takes place and it was analyzed theoretically. There is the need for change in the engineering education context as a result of the need for development of professional skills and technical skills. The study recommends that effort be placed more on research on digitization to ensure relevance with the current clime and also, researches in University of Cape Town should be tailored towards the Fourth Industrial revolution for relevance.

\section{REFERENCES}

1. Adams, J., Kaczmarczyk, S., Picton, P., \& Demian, P. (2010). Problem solving and creativity in engineering: conclusions of a three-year project involving reusable learning objects and robots. Engineering education, 5(2), 4-17.

2. American Science and Technology(2010). National Academy Press: $\begin{array}{lllll}\text { Washington, DC, USA, 2007. Available } & \text { online } & \text { at } \\ \text { http://www.academicjournals.org/JGRP.ISSN } & 2070-1845 & \text { (C)2010 } & \text { Academic }\end{array}$ Journals.

3. Barakabitze, A.A., E. J. Kitindi, C. Sanga, G. Kibirige, and N. Makwinya, "Exploring student's skills and attitudes on effective use of ICTs: case study of selected Tanzanian public secondary schools," Universal Journal of Educational Research, vol. 3, no. 6, pp. 407-425, 2015

4. Berggren, K. F., Brodeur, D., Crawley, E. F., Ingemarsson, I., Litant, W. T., Malmqvist, J., \& Östlund, S. (2003). CDIO: An international initiative for reforming engineering education. World Transactions on Engineering and Technology Education, 2(1), 49-52.

5. Borrego, M.; Beddoes, K.; Jesiek, B.K. International perspectives on the need for interdisciplinary expertise in engineering education scholarship. In Proceedings of the Australasian Association for Engineering Education Conference, Adelaide, Australia, 6-9 December 2009.

6. Borrego, M.; Bernhard, J. The emergence of engineering education research as an internationally connected field of inquiry. J. Eng. Educ. 2011, 100, 14-47.

7. Clarice, A. (2019). Here's why this road in Qatar has been painted blue. http://www.expatwoman.com/Qatar/things-to-do/events/heres-why-road-qatarhas-been-painted-blue

8. Cohen, L., Manion, L., \& Morrison, K. (2011). Research Methods in Education. New York: Routledge
9. Continental, A.G.(2006). "In Search of Global Engineering Excellence: Educating the Next Generation of Engineers for the Global Workplace". Hanover, Germany, Continental AG, 2006. (Available at http://www.contionline.com).

10. De Graaff, E., \& Ravesteijn, W. (2001). Training complete engineers: global enterprise and engineering education. European Journal of Engineering Education, 26(4), 419-427.December 2005. Nairobi, Kenya. African Union Paper. Available online on:

11. Deem, R., and K. J. Brehony. 2005. "Management as Ideology: The Case of 'New Managerialism' in Higher Education." Oxford Review of Education 31 (2): 217-35. https://doi.org/10.1080/03054980500117827.Educational Technology \& Society, vol. 15, no. 1, pp. 127-136, 2012.

12. Fatiregun, A.A. (1999): "A brief history of traditional African architecture (with 50 illustrations), Ilesa, Fatiregun press Ltd. Pp 11-37. for a Brighter Economic Future Committee on Prospering in the Global Economy of the 21st Century: An Agenda for

13. Globe Newswire. (2019). Education in South Africa. http://www.globenewswire.com/new-

release/2019/10/09/1927472/0/en/Education-in-South-Africa-2019-TheGovernment-have-allocated-R30-billion-toBuild-New-Schools-MaintainExisting-Infrastructure.html

14. Graham, R., \& Crawley, E. (2010). Making projects work: a review of transferable best practice approaches to engineering project-based learning in the UK. Engineering Education, 5(2), 41-49.

15. Grimson, J. (2002). Re-engineering the curriculum for the 21st century. European Journal of Engineering Education, 27(1), 31-37.

16. Hofstede, G. (1984). Cultures consequences. London: Sage publications, 1984.

17. http://acpculturesplus.eu/sites/default/files/2015/03/27/ua_afrmincult_cultureed ucation_2005_en.pdf

18. Jansen, J.D. (1998). Curriculum reform in South Africa: A critical analysis of outcomes-based education. Cambr J Educ. 1998;28(3):321-331. http:// dx.doi.org/10.1080/030576498028030

19. Kagerer, P. and Gandarilla, G. (2011). Current educational \& cultural challenges in construction. Hove, UK:RM/Insight. Available online at: www.asse.org., 2011

20. Melsa, J. (2007). Transforming engineering education through educational scholarship. Guest Ed. J. Eng. Educ. 2007, 96, 171-172.

21. Mgqwashu, E. (2016). Universities can't decolonise the curriculum without defining it first. The Conversation. Retrieved from https://theconversation.com/universities-cant-decolonise-the-curriculumwithout-defining-it-first-63948

22. National Academy of Engineering: Washington, DC, USA, 2010.

23. Neuman, W. L. (2006). Social research methods: qualitative and qualitative approaches (6 ed.). New York: Pearson

24. Nieuwenhuis, J. (2010). Introducing qualitative research. In K. Maree (Ed.), First steps in research. Pretoria: Van Schaik Publishers

25. Nuclear Regulatory Commission (NRC). (2009). Rising above the Gathering Storm: Energizing and Employing America

26. Obanya, P. (2005). Culture-in- education and education-in-culture. Fifth conference of African ministers of culture 10-14

27. Olotuah, A. O. (2001): "Mass Housing Design." Unpublished course monograph for Postgraduate Diploma students in architecture. Department of Architecture, the Federal university of technology, Akure. Pp. 2-9. on 15 May 2016].

28. Rikko L.S, and Gwatau, D. (2011): The Nigerian architecture: The trend in housing development. Journal of Geography and Regional Planning. Vol. 4(5), pp. 273-278.

29. Ruqayya B. T. (2011): Traditional Nigerian Architecture And Design Presentation for INTBAU and TAG Event, UK. 9-10th, February 2011.

30. Spencer-Oatey, H. (2012). What is culture? A compilation of quotations. GlobalPAD Core Concepts. Available at Global PAD Open House, 2012.

31. The Moka Consortium. (2001). "Managing Engineering Knowledge: MOKA Methodology for Knowledge Based Engineering Applications" ASME PRESS.New York.

32. Tomlinson, M. (2012). "Graduate Employability: A Review and Empirical Themes." Higher Education Policy 25 (4): 407-31. https://doi.org/10.1057/hep.2011.26.

33. Wankat, P.C., Bullard, L.G. (2016). The Future of Engineering EducationRevisited. Chem Eng Edu 2016;50(1):19-28. [13] Spinks N, Silburn N, Birchall D. Educating engineers for the 21st century: The industry view. London: Royal Academy of Eng; 2007.

34. White House Government. (2009).Obama's Campaign to Improve the Participation and Performance of America's Students in Science, Technology, Engineering, and Mathematics (STEM). "Educate to Innovate". 2009. Available online: http://www.whitehouse.gov/issues/education/educate-innovate (accessed on 26 June 2011

35. Zhu, C. Student satisfaction, performance, and knowledge construction in online collaborative learning. 